\title{
Ensino, Didática e Pesquisa Acadêmica na Educação Superior
}

\author{
Sandra Maria Rodrigues de Morais \\ UNI-BH - Ciência da Computação \\ smorais@acad.unibh.br
}

\begin{abstract}
Resumo. A Educação Superior no Brasil passa por mudanças estruturais em diversos níveis como seu processo de avaliação, formas de qualificação, modernizações curriculares, tipos de cursos, e outros. É preciso repensar também novas formas de atuação direta com aluno, em sala de aula. A recriação do processo de ensino e de aprendizagem é vital para que se estabeleçam vínculos fortalecedores entre o aluno, seu professor e o conteúdo desenvolvido nas disciplinas. A apresentação dos elementos básicos da dinâmica do ensino na universidade será focalizada neste trabalho numa revisão de posturas, escolhas e cuidados com o ensino na Educação Superior.
\end{abstract}

Palavras-chave: Educação Superior, Aluno, Ensino, Didática.

\begin{abstract}
The Higher Education in Brazil is going through structural changes at various levels as their evaluation process, types of qualifications, curriculum upgrades, types of courses, and others. We must also rethink new forms of work directly with students in the classroom. The recreation of the process of teaching and learning is vital to set stronger links between the student, his teacher and content developed in the disciplines. The presentation of the basic elements of the dynamics of teaching at university will be focused in this work a review of attitudes, choices and care with education in Higher Education.
\end{abstract}

Keywords: Teaching, Student, Didactic.

\section{INTRODUÇÃO}

Quem é este aluno que estou recebendo em minha turma? Esta é uma das primeiras indagações que o docente se faz ao iniciar um novo período letivo. A oportunidade é única e muito restrita, se considerarmos o tempo e o leque de disciplinas que interagirão em concomitância com a sua, para que façamos diferença no corredor universitário pelo qual o aluno perpassa.

Porém, esta primeira questão deveria ser seguida de outras também muito importantes: Como lidarei com esta turma, para que ao final de cada aula eu tenha modificado seu estado de saber? De que maneira desenvolver o trabalho pedagógico para que a disciplina aplicada seja um empreendimento pela vida acadêmica de meu aluno? Como podemos ser capazes de agregar transformações ao seu modo de pensar, agir, criar e realizar? São borbotões de dúvidas e incertezas, características positivas do ato do ensinar, porque se um educador inicia seu trabalho recheado de certezas em relação ao seu processo de ensino e ao processo da aprendizagem do aluno, então poderá ter uma visão distorcida daquele novo conjunto que irá se formar à medida que evoluírem as experiências decorrentes na sala de aula com o novo conjunto de alunos e professor.

E assim, poderá vir a criar uma discrepância de intenções, necessidades, significados e efeitos que tendem a se tornar cada vez mais contraditórios e crescentes, perdendo assim o momento do crescimento de todas as perspectivas, do professor, do aluno e do processo de construção do conhecimento. Atentar, também, para o fato de que esta evolução da disciplina desembocará em resultados 
quantitativos, enquanto que muitas de suas variáveis de percurso desenvolvem-se nos diferentes cenários qualitativos destas imbricadas relações.

Estes são os sinais refletidos na Educação Superior que provém das transformações que ocorrem na sociedade, que segundo Proa (1995), a "tradição inovadora", presente na academia o novo vai se tornando um mero vestígio, “[...] numa justa reciprocidade com o velho, que ganhará uma carga semântica similar". A dicotomia da convivência entre a tradição e a inovação é fenômeno de protagonismo da cultura. A academia faz emergir a ordem social de que o "novo" advém de um processo lento e quase imperceptível, onde as inovações iniciam-se no campo da ciência básica, chega à criação de novas tecnologias, que são selecionadas pelo mercado mundial, incorporadas à sociedade, submetidas à jurisprudência, utilizadas pelas forças políticas e econômicas, para, finalmente, serem reconhecidas pelo sistema educacional.

Toda esta longa trajetória faz parecer que a Educação é a última plataforma de geração de inovações e mudanças. Na verdade é um filtro para que as novas gerações não se confundam e esta evolução foi sintetizada por Proa (1995) ao considerar que "[...] o novo costuma ser um salto para trás, um retrocesso que, não obstante, será encarado como avanço exclusivamente porque corrige o curso e a perspectiva do imediato".

Há, portanto, que se reflexionar sobre o "novo" que se instalou na Educação Superior na última década, quando, a partir das estruturas de seu funcionamento como as composições democráticas dentro das universidades; a multiplicação de unidades de Educação Superior; a recomposição de cursos, disciplinas, números de períodos; a introdução de cursos de graduação seqüenciais e tecnológicos; o grande aparato nacional do processo de auditorias, avaliações e classificações das instituições, em listas divulgadas pelas mídias; as mudanças no sistema de ingresso, vestibulares; a necessidade de se produzir academicamente o conhecimento; além, da implantação de bolsas e programas de inclusão mais democrática para variados níveis e instâncias sociais.

A resultante de todas estas inovações e implementações foi a dedicação do sistema de Educação Superior a cumprir as exigências destas reestruturações e "novidades", porém a discussão sobre a dinâmica ocorrida em sala de aula fica relegada a uma desimportância que tem incomodado ao docente ao ter a percepção de que o efeito de seu trabalho mal arranha a superfície do aluno, e, sente desconforto quando avalia o baixo nível agregador de sua disciplina na constituição dos saberes de seu aluno.

É, precisamente, este fator de problematização, o de alcançar um equilíbrio entre as necessidades formalizadoras do contexto da Educação Superior, às necessidades balizadas pelo aluno que refletem as ressonâncias sociais, que apresentamos a questão condutora deste trabalho: Que estratégias de ensino o professor da Educação Superior pode se apropriar, reformular ou inovar para desenvolver um trabalho docente que contribua mais com a produção de saberes substantivos em direção aos interesses e necessidades do aluno, preservando a consistência do conhecimento? Esta questão pode ter aparência paradoxal. Mas, em verdade, estes objetivos que parecem divergentes só acontecem numa relação de equivalência: maior qualidade do trabalho docente eleva a qualidade da aprendizagem do aluno, e, quanto mais bem preparado for o aluno, maior será solicitado o desempenho do trabalho docente. 
A pesquisa que fundamentou este trabalho da área das ciências humanas tem o objetivo de ser descritiva, produto resultante de pesquisa científica, cujo procedimento técnico utilizado foi a pesquisa bibliográfica, de caráter empírico. Tem por finalidade fornecer explicações sistemáticas que podem ser criticadas e discutidas intersubjetivamente. Portanto, podemos classificar esta investigação como aplicada, com objetivos descritivos, tendo como fonte de coleta de dados a pesquisa bibliográfica, de natureza qualitativa.

Para o desenvolvimento de nossa investigação, é preciso que definamos alguns termos que esclarecem ao leitor a direção que se pretende alcançar e que são capazes de orientar ao docente na escolha de opções que são mais interessantes para conduzir seu trabalho didático $\mathrm{e}$ pedagógico.

\section{Definições simplificadas e significantes}

O primeiro termo abordado foi a Educação Superior. Normalmente, ouvese Ensino Superior, mas com a nova LDB, Lei de Diretrizes e Bases da Educação Nacional $\mathrm{n}^{\circ}$ 9.394/96, a Educação Superior é o segundo nível da Educação Nacional, antecipado pela Educação Básica, compreendendo a Educação Superior os níveis da Graduação e PósGraduação, (Brasil, 1996). Por Educação pode-se, de maneira elementar, circunstanciá-la como o processo de modificação do estado do saber dos indivíduos. Carlos Rodrigues Brandão, em seu livro "O que é Educação", aprimora o entendimento sobre este conceito de instituição popular:

A educação é, como outras, uma fração do modo de vida dos grupos sociais que a criam e recriam, entre tantas outras invenções de sua cultura, em sua sociedade. [...] E aparece sempre que surgem formas sociais de condução e controle da aventura de ensinar-eaprender. [...] O ideal da Educação é reproduzir uma ordem social idealmente concebida como perfeita e necessária. (BRANDÃO, 2001).

Acrescente-se que a Educação pode acontecer em contexto sistematizado e assistematizado, dentro de uma instituição de ensino formal, ou, em qualquer outro espaço da sociedade e das relações sociais que se vinculem à “[...] mudança social, à pessoa na sociedade, à formação conseqüente de sujeitos e agentes na /da mudança social", (Brandão, 2001). Assim, entende-se que Educação é um processo social ativo que tem objetivos políticos, sociais, econômicos e científicos, exigindo uma relação de interdependência entre os sujeitos que ensinam e os sujeitos que querem ou que devam aprender, extraindo daí a conservação e renovação da sociedade, seus grupos sociais e interesses e acervo cultural. Para Gandin (2002) Educação é:

Um conjunto de recursos, situações e ações para que mais facilmente aconteça o educar-se. A. Educar-se é em primeiro lugar, projetar e buscar a própria identidade, seja pessoal, seja do grupo. B. Educar-se é, em segundo lugar, dotar-se de instrumentos para participar na sociedade. [...] assim, analisando a escola como um todo julgo que ela se resume a três fins básicos que deveriam ser buscados harmoniosamente: a) a formação do ser humano; b) o desenvolvimento da ciência; c) o domínio da técnica. (GANDIN, 2002).

Analisando a perspectiva de Gandin podemos defini-la como ousada, pois recai sobre a Educação o alicerce da sociedade em seus aspectos culturais, humanistas, científicos e tecnológicos, ou seja, a evolução da vida e da obra humanas. E, a partir daí começa-se a perceber a extensão e o valor que toma a arte do ensinar que está a cargo dos professores, sejam em seu exercício formal ou informal.

Quanto à Pedagogia, saber que administra os processos de ensino e de aprendizagem. Ou, de forma mais consistente, podemos definir, de forma simplificada o pedagogizar como a tarefa 
social de conduzir, administrar, desenvolver processos e pessoas nos caminhos da construção de conhecimentos. A Pedagogia é um campo de conhecimento que tem por finalidade produzir a reflexão teórica a partir e sobre as práticas educativas, (Libâneo, 2005). Ressalte-se que a tendência brasileira é a de substituir o campo teórico-investigativo da Pedagogia (função pedagógica) pelo exercício da licenciatura (docência), na Educação Básica.

Todo professor deveria ser um pedagogo em essência, pelo fato de que é de sua responsabilidade desenvolver a competência da administração, com maior dimensão de êxito, do processo de ensino que é o mote para que aconteça o segundo processo convergente, a aprendizagem do aluno. Mas, a maioria dos docentes, provenientes de cursos superiores não voltados à licenciatura, durante sua formação na Educação Superior, passou por um currículo que privilegiava o ensino de disciplinas técnico-operacionais da área do curso e, poucas disciplinas voltadas à Educação e ao Ensino. E, atualmente, com as exigências do mercado de trabalho em relação à elevação do nível educacional dos candidatos, é comum aos certificados em nível de strictu sensu (mestrado, doutorado e pós-doutorado) assumir a docência nas instituições de Educação Superior, que deve cumprir o número exigido pelo MEC, ministério da Educação, de docentes/certificações, com poucas horas de experiência didáticopedagógica, dificultando $\mathrm{o}$ andamento mais ajustado dos processos pedagógicos.

Já a Didática é a poderosa ferramenta que o docente precisa dominar para gerir seu processo de ensino. Sem o apoio da Didática o docente tenderá a realizar seu trabalho com os alunos experimentando e aprendendo com seus erros e acertos, o que não é o recomendável. Pior é se considerarmos que a maior tendência do docente que não se fundamenta na ciência educacional é o fato de ter como referência a própria vida escolar pelo qual vivenciou, repetindo comportamentos que mais lhe marcaram em sua perspectiva de aluno, ou seja, ainda perpetua a forma de ensinar que lhe foi transmitida por seus professores, representantes de outro cenário educacional, já superado.

Especificamos a Didática, através da contribuição de Candau (1994) que a apresenta como:

[...] um "elo de tradução" dos conhecimentos produzidos pelas disciplinas, pois trata-se de conhecimento de mediação, sua especificidade é garantida pela preocupação com a compreensão do processo de ensino-e- aprendizagem e a busca de formas de invenção na prática pedagógica. A didática tem por objetivo o "como fazer" a prática pedagógica, mas este só tem sentido quando articulado ao "para que fazer" e ao "por que fazer". (CANDAU, 1994).

A partir da Didática o professor procurará adaptar diferentes ferramentas e estratégias que facilitem o desenvolvimento da disciplina optando pela conjugação de diferentes fatores, tais como:

O tipo de plano de trabalho a desenvolver:

a) As abordagens de ensino, que dependem de cada tipo de disciplina, se mais técnica ou mais aplicativa; se mais fundamentada na leitura ou na troca de idéias e estudos de conflitos; se mais individual ou se mais coletivo; e outras possibilidades;

b) A ordem dos conteúdos a serem apresentados à turma;

c) Os objetivos a alcançar ao final das unidades de ensino, além de sua medida de efetividade;

d) As metodologias a selecionar para corresponderem aos conteúdos a apresentar;

e) As técnicas diversificadas que deverá lançar mão para que explorem ao máximo o potencial de aprendizagem do aluno; 
f) Os materiais, os meios, os equipamentos e espaços a serem selecionados para consolidarem a aprendizagem do aluno; e,

g) Os tipos de avaliações necessárias, não para eliminar possibilidades do aluno ou medir aquilo que ele não sabe, mas para tornar-se mais uma etapa que fortaleça os processos de ensino e de aprendizagem. Outra ocasião de aprendizagem.

Reforçando, a Didática é o "como", o "para quê" e o "por quê" que o docente define previamente em seu plano de ações para melhor desenvolver seu trabalho pedagógico, evitando desvios de sua intenção intrínseca de qualificar seu trabalho.

O Ensino por sua vez é o objeto de estudo da Didática. Ensino não deve ser confundido com Educação. A Didática estuda o Ensino e suas formas de condução. Selecionamos a contribuição de Luaiza (2009) para clarificar o conceito de ensino que é muito confundido com Educação e aprendizagem;

\footnotetext{
O ensino é um processo bilateral de ensino e aprendizagem. Daí, que seja axiomático explicitar que não existe ensino sem "aprendizagem". Seu posicionamento sempre foi muito claro, quando estabeleciam entre ensino e aprendizagem, uma unidade dialética.

A linha fundamental do processo de ensino é a transmissão e apropriação de um sólido sistema de conhecimentos e capacidades duradouras e aplicáveis. O ensino é como o processo de organização da atividade cognoscitiva, processo que se manifesta de uma forma bilateral: a aprendizagem, como assimilação do material estudado ou atividade do estudante, e o ensino como direção deste processo ou atividade do professor. (LUAIZA, 2009).
}

O ensino é a função maior do docente, a ele compete a responsabilidade para o ensinar, e, como conseqüência, o aluno pode ou não aprender. Há uma discussão entre teóricos da Educação que analisam se quando o aluno não aprende então não haveria ensino e aí se frustra o trabalho aplicado do professor. Frize-se que deve haver dialógica entre os processos dialéticos de ensino e aprendizagem, porém o ensino é a ação concretizada pelo professor com todas as suas variáveis e a aprendizagem é o resíduo construído pelo próprio aluno que foi estimulado pelo professor.

Para que se ensine é necessário que o docente considere várias interfaces entre ele, o aluno e o conhecimento. Ressalte-se para a compreensão desta relação a proposta apresentada por Charlot (2000) que fundamenta a teoria da relação com o saber, organizada através dos seguintes elementos correlacionais da dimensão do ensino:

a) $\mathrm{O}$ sujeito, primeiro elemento estruturador do processo;

b) As relações simétricas e assimétricas construídas na sala de aula;

c) A motivação como o núcleo da dinâmica do desejo de ensinar e de aprender;

d) $\mathrm{O}$ sujeito falante, oralizador, contributivo;

e) O sujeito ouvinte, receptivo;

f) O sujeito atuante, realizador, criativo;

g) A construção histórica articulada com a família, a sociedade, a condição humana;

h) O nível de engajamento de consciência de mundo, na posição que ocupa e inscreve suas relações sociais; e,

i) O sujeito interveniente, organizador, estimulador, avaliador, o professor.

São, portanto, muitos os componentes necessários à concorrência para que o ensino seja bem sucedido levando a um maior percentual de aprendizagem na aplicação de uma disciplina. É uma tarefa trabalhosa e atenta.

Para completar a análise destes processos da relação aluno-professordisciplina é imperativo que se aborde a questão da pesquisa acadêmica e sua importância na trajetória do aluno de instituições de Ensino Superior. 


\section{A pesquisa acadêmica}

A universidade se apóia em um tripé que integra as dimensões do Ensino, Pesquisa e Extensão. Já se abordou a questão do ensino, que se realiza na interação dialógica entre o aluno, o professor e o saber. A Extensão se configura como a participação da universidade junto às comunidades, levando sua produção científica e aprendendo e recolhendo dados na realidade da sociedade. A Pesquisa faz parte de um contexto mais amplo de pesquisa na universidade brasileira que se fundamenta no trabalho de pesquisa e que envolve a produção literária, de estudos, experimentações, projetos de pesquisa e outras iniciativas que estabelecem o patamar de qualificação da unidade de Educação Superior, que resulta na classificação nacional, pelo MEC.

A visão da pesquisa acadêmica que queremos abordar é mais restrita, se configura na realização de atividades de aprendizagem para o aluno e oportunidade de concretização do processo de ensino por parte do professor, que integra o saber à investigação e interação do aluno, seja individual, ou com outros colegas, com materiais e fontes diversificados e que exijam um retorno criador por parte do aluno, e não, um mero trabalho de cópia de autores e produções alheias.

É importante que o professor aplique os fundamentos didático-pedagógicos para organizar a realização da pesquisa acadêmica. Sugerem-se algumas possibilidades que facilitem a aplicação da pesquisa acadêmica de forma produtiva. Pode-se atentar para os seguintes detalhes que são simples e facilmente integrados na pauta didática da academia:

a) Preparar de forma detalhada a orientação de pesquisa que contenha seus objetivos; temas e subitens; o produto esperado; as formas de apresentação; $\quad$ o cronograma consensado; o dimensionamento do assunto pesquisado; os indicadores de avaliação; e, o valor atribuído à atividade de pesquisa.

b) Verificar se os alunos têm acesso a manuais de normalização institucional com modelo referenciado na ABNT Associação Brasileira de Normas Técnicas; ou, indique fontes que possibilitarão uma unanimidade de normas a serem aplicadas a todas as pesquisas apresentadas, para que não ocorram dúvidas e descontentamentos;

c) Indicar, caso seja necessário, fontes de pesquisa que sejam indispensáveis para que o aluno desenvolva seu trabalho, com material que lhe propicie base e fundamentos adequados e necessários ao desenvolvimento de sua pesquisa;

d) Verificar o nível da produção da turma e valorize, especialmente, aos trabalhos que construíram o conhecimento e não apenas repetiram o que já estava disponível;

e) Preparar aos alunos que se projetaram para aprofundar sua produção e disponibilizá-la em meios de divulgação, editoriais, páginas na internet, e outras possibilidades. Reforçando assim, a importância e o caráter de autonomia e realização provenientes desta atividade pedagógica;

f) Definir desde o início dos cursos a aplicação das normas da ABNT para todas as disciplinas tornando-se uma rotina incorporada às práticas do aluno e facilitando assim a elaboração de seu TCC - Trabalho de Conclusão de Curso, que exige rigor investigativo combinado com a criação/abstração e, se o aluno possui constituído o saber e uso das normas técnicas aumentará sensivelmente a qualidade de sua produção, pois sua concentração será maior nos resultados de sua pesquisa.

Assinale-se que o docente não desvalorize o potencial cognitivo 
intrínseco ao ato de pesquisar. $\mathrm{O}$ aluno ao utilizar esta efetiva ferramenta geradora de autonomia, senso de realização, extrapolação de aprendizagens, desenvolve capacidades e habilidades permanentes que incidirão sobre sua forma de observar, agir, analisar, questionar suas experiências de todos os níveis. Brito Cruz (2004) expõe uma reflexão que condensa este poder gerador da pesquisa:

A força da Universidade não está no pretenso monopólio sobre o conhecimento. Está, sim, na capacidade de gerar um tipo especial de conhecimento, na habilidade em trabalhar com ele e, principalmente, na competência em formar e educar pessoas para continuarem a executar ambas as tarefas. A força da universidade, sua característica mais singular, está na aliança entre educação e avanço do conhecimento. A pesquisa básica passa a ser muito importante para ajudar a formar estudantes, pois permite o treinamento da mente de maneira eficaz, usando o prazer da descoberta, sem outra cobrança que não a do compromisso com o método científico. (BRITO CRUZ, 2004).

É característica cultural brasileira acreditar mais nas elaborações míticas do que nas evidências científicas, não que isso desvalorize nossa sociedade, na verdade faz parte do povo brasileiro esta criatividade e poder de superar as diversidades e adiversidades através de explicações que amenizem o realismo. Temos crescido muito através de alguns assuntos mais veiculados pelas mídias, procurando encontrar mais lógica e racionalidade do que fantasias. Por isso é mais difícil para o aluno colocar em prática a linearidade exigida pela metodologia científica, quando a tendência é a do pensamento radial.

Quando o aluno ingressa nos cursos de graduação tem que passar a superar as meras suposições para tomar decisões e opiniões consistentes e argumentativas a partir de informações concretas, específicas e comprovadas. É um grande salto! Por isso a relevância da Metodologia Científica e das Técnicas de
Pesquisa para estudantes, que consistem em desenvolver habilidades de investigação, observação, reflexão, análise e solução de problemas, e, o registro formal e objetivo que exige a produção científico-metodológica. E os passos mais difíceis para o professor são os de desenvolver esta aprendizagem através do ensino das seguintes habilidades:

- Resolução de problemas;

- Identificação de oportunidades;

- Coleta de dados;

- Análise de dados e resultados;

- Tomada de decisão baseada em fatos e não em "achismos"; e,

- Conclusões registradas e personalizadas.

Evidencia-se pelos gráficos abaixo apresentados a estimativa crescente da produção acadêmica do Brasil.

Figura 1. Superior: Número de artigos científicos publicados em revistas de circulação internacional, originados no Brasil de 1981 a 2003.

Figura 2. Inferior: Número de doutores formados no Brasil, de 1981 a 2003.
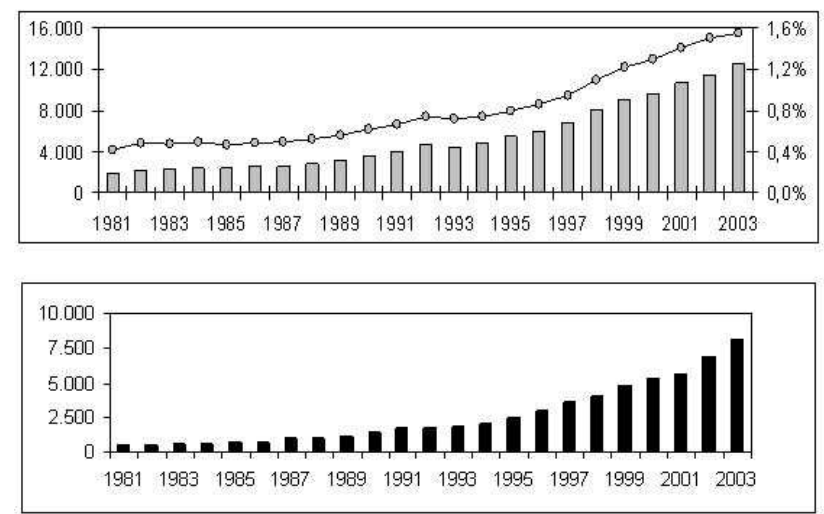

Fonte: MEC, 2004.

O objetivo da universidade deve, portanto, ser a aprendizagem e a produção da investigação. Sua análise e síntese consubstanciadas nas últimas duas décadas evidenciam uma crescente tendência à produção acadêmica originada da pesquisa. Portanto, sua aprendizagem deve ser acompanhada pelo professor 
criando hábitos básicos no aluno para produzir um trabalho sério, ético, sem reproduções e reforçando a problematização, a metodologia científica, a análise e a síntese em sua elaboração. Levar o aluno a perceber que ao final de seu trabalho, há um resultado que ele próprio conquistou e que acrescenta uma nova contribuição àquele tema de pesquisa.

\section{E afinal, quem é este aluno?}

A UEL - Universidade Estadual de Londrina, no Paraná, divulgou um estudo sobre o perfil dos alunos de graduação que ingressaram na UEL, em 2003. Corresponde a informações sobre as condições sócio-econômicas, educacionais e culturais. Este acesso foi facilitado pela instituição que o divulgou na web e que contém uma extensa apresentação da comunidade ingressante na unidade de Educação Superior. Selecionamos apenas três tópicos deste estudo, mas já nos dá um referencial básico para desvelarmos que aluno é este que recebemos na educação superior. É claro que diferenças ocorrem por todo o território nacional, porém o acesso a este tipo de informação é muito restrito e esperamos possam indicar reflexões propostas considerando este subtítulo.

Os dados a conhecer foram obtidos através dos questionários preenchidos pelos alunos na ocasião das matrículas dos alunos aprovados no vestibular. Destacam-se e totalizam-se somente os questionários dos alunos que obtiveram classificação para o preenchimento das vagas oferecidas. Trata-se, portanto, de uma amostra significativa, composta de todos os alunos, de todos os cursos, matriculados no primeiro ano, o que corresponde a $22,10 \%$ do universo da população discente da graduação, no

Tabela 1. Renda familiar mensal - Geral
Opção alunos mesmo período. Ao todo, os dados se referem a uma população de 3.019 alunos.

Há grande necessidade de referenciar o trabalho docente "visualizando" o tipo de aluno que recebemos, conforme Ricardo de Jesus Silveira, Diretor de Avaliação e Acompanhamento Institucional, da UEL, que registra na Introdução da pesquisa:

\begin{abstract}
Parece-nos desnecessário salientar a importância de termos conhecimento sobre a população discente da Universidade, pois é sabido que a sua desconsideração nos leva, muitas vezes, a procedimentos incorretos do ponto de vista administrativo e/ou acadêmico. Procedimentos que, se não dimensionados corretamente, põem a perder todo esforço e dispêndio de recursos que são reunidos para que a universidade cumpra os seus objetivos de produção de saber e de ensino, tendo em vista a construção de uma sociedade pautada na justiça social. (SILVEIRA, 2003).
\end{abstract}

Segundo a pesquisa realizada, e disponobilizada à comunidade acadêmica, analisemos alguns dados importantes, conforme (Silveira, 2003):

\section{- Dados socioeconômicos:}

Evidenciam que $30,57 \%$ dos alunos sejam provenientes de famílias com renda na faixa de até $\mathrm{R} \$ 1.000,00$ mensais, dados que correspondem, quando feita a coleta, a 5 salários mínimos, (Tabela 1). Fica também registrada na pesquisa (Silveira, 2003) a análise mais apurada de que "O mesmo raciocínio estende-se para o percentual de alunos que trabalham: dos $34,45 \%$ dos alunos da UEL, 45,20\% deste universo são de alunos de humanas, e $60,80 \%$ concentram-se nos cursos do noturno, sendo que, de todos os alunos que trabalham $28,52 \%$ contribuem diretamente com a renda familiar", (Tabela 2).

\begin{tabular}{|r|c|c|}
\hline Não informado & $\mathbf{5 7}$ & $\mathbf{1 , 8 9}$ \\
\hline Até $R \$ 200,00$ & $\mathbf{2 7}$ & $\mathbf{0 , 8 9}$ \\
\hline de $R \$ 201,00 \mathrm{a}$ & $\mathbf{3 3 7}$ & $\mathbf{1 1 , 1 6}$ \\
\hline
\end{tabular}




\begin{tabular}{|c|c|c|}
\hline $\mathrm{R} \$ 600,00$ & & \\
\hline $\begin{array}{r}\text { de } R \$ 601,00 a \\
R \$ 1.000,00\end{array}$ & 559 & 18,52 \\
\hline $\begin{array}{r}\text { de } R \$ 1.001,00 a \\
R \$ 1.400,00\end{array}$ & 473 & 15,67 \\
\hline $\begin{array}{r}\text { de } R \$ 1.401,00 \text { a } \\
R \$ 2.000,00\end{array}$ & 467 & 15,47 \\
\hline $\begin{array}{r}\text { de } R \$ 2.001,00 \mathrm{a} \\
R \$ 3.000,00\end{array}$ & 423 & 14,01 \\
\hline $\begin{array}{r}\text { de } R \$ 3.001,00 a \\
R \$ 4.000,00\end{array}$ & 275 & 9,11 \\
\hline $\begin{array}{r}\text { de } R \$ 4.001,00 \mathrm{a} \\
R \$ 5.000,00\end{array}$ & 155 & 5,13 \\
\hline $\begin{array}{r}\text { de } R \$ 5.001,00 a \\
R \$ 6.000,00\end{array}$ & 96 & 3,18 \\
\hline $\begin{array}{c}\text { Acima de } \\
\mathrm{R} \$ 6.000,00\end{array}$ & 150 & 4,97 \\
\hline Total & 3019 & 100 \\
\hline
\end{tabular}

Fonte: UEL, 2009

Tabela 2. Alunos que trabalham - Geral

\begin{tabular}{|l|c|c|}
\hline \multicolumn{1}{|c}{ Opção } & $\mathbf{N}^{\mathbf{0}}$ de alunos & $\boldsymbol{\%}$ \\
\hline Não informado & $\mathbf{4 5}$ & $\mathbf{1 , 4 9}$ \\
\hline Sim & $\mathbf{1 0 4 0}$ & $\mathbf{3 4 , 4 5}$ \\
\hline Não & 1934 & $\mathbf{6 4 , 0 6}$ \\
\hline Total & $\mathbf{3 0 1 9}$ & $\mathbf{1 0 0}$ \\
\hline
\end{tabular}

Fonte: UEL, 2009

$\mathrm{O}$ acesso particular à internet também é um diferencial para gerar a autonomia do aluno, principalmente, aquele que trabalha e não tem acesso ilimitado a esta importante ferramenta de estudo.

Tabela 3. Propriedade de computador

\begin{tabular}{|l|c|c|}
\hline \multicolumn{3}{|c|}{ Com acesso à internet - Geral } \\
\hline Não informado & $\begin{array}{c}\mathbf{N}^{\mathbf{o}} \text { de } \\
\text { alunos }\end{array}$ & $\%$ \\
\hline Não & $\mathbf{3 9}$ & $\mathbf{1 , 2 9}$ \\
\hline Possuo um & $\mathbf{1 1 9 7}$ & $\mathbf{3 9 , 6 5}$ \\
\hline Possuo mais de um & $\mathbf{1 6 5 6}$ & $\mathbf{5 4 , 8 5}$ \\
\hline Total & $\mathbf{1 2 7}$ & $\mathbf{4 , 2 1}$ \\
\hline
\end{tabular}

Fonte: UEL, 2009

\section{- Características sócio-educacionais dos alunos:}

Segundo análise de Silveira (2003), na Tabela 4, tomando o pai como referência temos $19,44 \%$ de freqüência de $1^{\circ}$ grau incompleto e $8,18 \%$ de completos. Adicionando também os pais sem escolaridade, $2,42 \%$, significa que $30,04 \%$ dos pais, que agora têm os seus filhos chegando à universidade, não conseguiram ultrapassar o ensino fundamental. No noturno, esse percentual sobe para $44,95 \%$. Com relação ao $2^{\circ}$ grau, observa-se que dos $60,12 \%$ dos pais que concluíram o $2^{\circ}$ grau, $39,52 \%$ e chegaram à universidade, sendo $23,42 \%$ concluintes e $6,89 \%$ chegaram à pósgraduação.

Tabela 4. Nível de instrução do pai - Geral

\begin{tabular}{|c|c|c|}
\hline Opção & $\begin{array}{l}\mathrm{N}^{\circ} \text { de } \\
\text { alunos }\end{array}$ & $\%$ \\
\hline Não informado & 290 & 0,96 \\
\hline Sem escolaridade & 73 & 2,42 \\
\hline $\begin{array}{l}\text { Ensino Fundamental } \\
\text { (1으 Grau) incompleto }\end{array}$ & 587 & 19,44 \\
\hline $\begin{array}{l}\text { Ensino Fundamental } \\
\text { (1ํ Grau) completo }\end{array}$ & 247 & 8,18 \\
\hline $\begin{array}{l}\text { Ensino Médio } \\
\left(2^{\circ} \mathrm{Grau}\right) \text { incompleto }\end{array}$ & 190 & 6,29 \\
\hline $\begin{array}{l}\text { Ensino Médio } \\
\text { (2 Grau) completo }\end{array}$ & 622 & 20,60 \\
\hline Superior incompleto & 279 & 9,24 \\
\hline Superior completo & 707 & 23,42 \\
\hline $\begin{array}{l}\text { Curso de Pós- } \\
\text { Graduação }\end{array}$ & 208 & 6,89 \\
\hline Não sei informar & 77 & 2,55 \\
\hline Total & 3019 & 100 \\
\hline
\end{tabular}

Analisando a Tabela 5, verifica-se que a universidade não recebe a maioria dos privilegiados sociais. Há equivalência entre os mais e os menos privilegiados sociais.

Tabela 5. Estudou o $\mathbf{1}^{\mathbf{0}}$ grau em escola pública, privada ou outro - Geral

\begin{tabular}{|l|c|c|}
\hline \multicolumn{1}{|c|}{ Opção } & $\begin{array}{c}\mathbf{N}^{\mathbf{0}} \text { de } \\
\text { alunos }\end{array}$ & $\mathbf{\%}$ \\
\hline Não informado & $\mathbf{2 8}$ & $\mathbf{0 , 9 3}$ \\
\hline $\begin{array}{l}\text { Integralmente em } \\
\text { escola pública }\end{array}$ & $\mathbf{1 5 7 3}$ & $\mathbf{5 2 , 1 0}$ \\
\hline Integralmente em & $\mathbf{7 7 3}$ & $\mathbf{2 5 , 6 0}$ \\
\hline
\end{tabular}




\begin{tabular}{|c|c|c|}
\hline escola particular & & \\
\hline $\begin{array}{l}\text { Maior parte em } \\
\text { escola pública }\end{array}$ & 329 & 10,90 \\
\hline $\begin{array}{l}\text { Maior parte em } \\
\text { escola particular }\end{array}$ & 311 & 10,30 \\
\hline $\begin{array}{l}\text { Em comunitárias } \\
\text { CNEC ou outro }\end{array}$ & 5 & 0,17 \\
\hline Total & 3019 & 100 \\
\hline
\end{tabular}

Fonte: UEL, 2009

\section{- Características culturais dos alunos:}

Na Tabela 6, considerada para este estudo a mais importante para ser analisada e compreendida, observa-se que o aluno ingressante na universidade tende a ter expectativas de grande força moral e cidadã. Esses dados permitem-nos pensar a Universidade como espaço de construção de conhecimentos voltados para os valores éticos de uma sociedade mais justa e humana, além de ter o poder de preparar o aluno para construir uma vida digna a partir do mundo do trabalho a ingressar ou a aperfeiçoar. Esta é uma expectativa real que observamos ao constatar que $11,69 \%$ dos alunos esperam do curso "...conhecimentos que permitam melhor compreender o mundo..." e que

\section{Considerações finais}

Retomando as questões iniciais propostas verifica-se que existem alternativas pedagógicas que implementam o trabalho docente para criar estratégias de ensino que contribuam de maneira mais eficiente e eficaz para que o aluno tenha menos dificuldades na elaboração de conhecimentos e saberes. A exigência em relação ao docente é de se atualizar permanentemente, considerar cada turma com personalidades e necessidades distintas.

Para lidar com a turma de trabalho o docente deve se preparar planejando,
$9,14 \%$ esperam adquirir "...cultura geral e ampla".

Tabela 6. O que esperar do curso universitário Geral

\begin{tabular}{|lcc|}
\hline \multicolumn{1}{|c}{ Opção } & $\begin{array}{c}\mathbf{N}^{\mathbf{0}} \text { de } \\
\text { alunos }\end{array}$ & $\mathbf{\%}$ \\
\hline Não informado & $\mathbf{3 6}$ & $\mathbf{1 , 1 9}$ \\
\hline $\begin{array}{l}\text { Formação profissional } \\
\text { voltada para o trabalho }\end{array}$ & $\mathbf{1 8 2 9}$ & $\mathbf{6 0 , 5 8}$ \\
\hline $\begin{array}{l}\text { Formação teórica } \\
\text { voltada para a pesquisa }\end{array}$ & $\mathbf{1 5 8}$ & $\mathbf{5 , 2 3}$ \\
\hline $\begin{array}{l}\text { Formação acadêmica } \\
\text { para melhorar a atividade } \\
\text { profissional que já estou } \\
\text { desempenhando }\end{array}$ & $\mathbf{1 7 1}$ & $\mathbf{5 , 6 6}$ \\
\hline $\begin{array}{l}\text { Formação para } \\
\text { atividade pedagógica }\end{array}$ & $\mathbf{1 3 9}$ & $\mathbf{4 , 6 0}$ \\
\hline $\begin{array}{l}\text { Aquisição de conhecimentos } \\
\text { que me permitam } \\
\text { compreender melhor o } \\
\text { mundo em que vivemos }\end{array}$ & $\mathbf{3 5 3}$ & $\mathbf{1 1 , 6 9}$ \\
\hline $\begin{array}{l}\text { Aquisição de cultura } \\
\text { geral ampla }\end{array}$ & $\mathbf{2 7 6}$ & $\mathbf{9 , 1 4}$ \\
\hline \begin{tabular}{l} 
Diploma de curso superior \\
\hline \begin{tabular}{l} 
Total \\
\hline
\end{tabular}
\end{tabular} & $\mathbf{5 7}$ & $\mathbf{1 , 8 9}$ \\
\hline
\end{tabular}

Fonte: UEL, 2009

reorganizando seu trabalho do ponto de vista pedagógico e didático, adaptar seu conteúdo à uma transposição didática, de acordo com o que o aluno prescinde e não com o hábito de seguir um livro didático e sua distribuição de conteúdos e exercícios. Tratar o material didático como ponto de apoio, ao contrário da rotina de se usá-lo como fonte inquestionável de conhecimentos.

Momentos como os de corrigir uma atividade são preciosos, pois é lá que o aluno se confronta com sua elaboração e a de seus colegas. Daí, a força do professor para levar o aluno a sempre cumprir com seu cronograma de atividades e tarefas, em que cada caso exigirá posturas e reações diferentes do professor. 
O prazer pela descoberta deve ser programado pelo docente e não um mero fruto do acaso; as atividades planejadas devem incorporar a pergunta, a pesquisa, o desejo de resolver desafios e problemas. $\mathrm{O}$ aluno não deve entrar em sala de aula para assistir à aula, ele deve estar na sala para participar, resolver, pesquisar, perguntar, duvidar, compartilhar e, aprender, se modificar, se transformar.

O mais difícil do papel do professor é fazer com que o aluno tenha a certeza de que sua disciplina é muito importante, extensão do sentimento de cada professor. Para ser um docente é importante que se integrem as dimensões:

- Ser profissional, ou cumprir com suas obrigações de trabalhador: ser pontual, devolver as correções em tempo desejável e aproveitável; realizar a chamada no dia letivo; entregar as notas dentro do prazo; e outras ações que organizem sua ação.

- Ser professor, ou cumprir com sua dimensão do ensinar para o aprender; conhecer seu conteúdo; usar as ferramentas didáticas disponíveis; aplicar os princípios pedagógicos ao seu processo de trabalho; planejar, ensinar, acompanhar, orientar e avaliar o aluno, bem como o seu progresso em sala de aula.

- Ser educador, ou cumprir com seu papel social de observar ao aluno, seu comportamento, suas atitudes. Este conjunto proporcionará ao professor se antecipar a possíveis problemas que poderiam impedir ao aluno de aprender, encaminhando-o a outros profissionais como os orientadores educacionais e psicólogos. Vale também uma boa conversa em que o aluno sente que está sendo acompanhado e impelido a se reformular na disciplina.

O aluno prescinde de ajuda, pois grande parte é proveniente da educação básica que têm pais que não freqüentaram a universidade e, muitos cursaram a Escola Pública, não que se predetermine sua desqualificação, mas na escola privada de ensino médio, ao aluno é dada uma preparação, mesmo que ínfima, para ingressar na Educação Superior, faz parte da estrutura desse segmento de ensino. Esta ajuda do professor pode ser traduzida em acompanhar de forma regeneradora das bases dos pré-requisitos dos conteúdos, da orientação personalizada, da avaliação em tempo real e do olhar: ferramenta de aproximação e consolidação da confiança do aluno em relação ao professor.

É fundamental que se preserve a motivação do aluno que inicialmente o conduziu à universidade, e que esta predisposição, conforme descrita na pesquisa apresentada, necessita ser aprimorada através de práticas didáticas que têm como princípio ajudar ao professor a ensinar para que o aluno possa aprender: é um trabalho concomitante, dialético que deve construir a essência do interativo e da cumplicidade entre ambos. A motivação recriada é ponte para o desejo de aprender.

A formação para a pesquisa é fundamental, pois se o aluno pretende compreender o mundo, atuar no mercado de trabalho, elevar sua condição profissional, é derivativa a preparação para a problematização, investigação e organização racional de resultados. Em todos os níveis profissionais da contemporaneidade esta qualificação é indispensável. Além de ser a linguagem mais evidenciada da qualidade de uma unidade de Educação Superior na contemporaneidade.

Para se predispor a ser um professor em Educação Superior, é premente que o docente tenha a sensibilidade de se avaliar permanentemente, através de ações como: 
- Conhecer de maneira bem objetiva o aluno que está sob sua responsabilidade;

- Enxergar o conteúdo através do olhar do aluno; a condição da empatia presente;

- Saber que para ensinar existe uma tecnologia de ensino, ou seja, um conjunto de técnicas inteligentes e provenientes da Didática e das estratégias de ensino;

- Discernir que no ensino de qualquer disciplina há necessidade do professor se atualizar sobre o conteúdo, a forma de abordagem, e, mais que tudo, que outros professores também têm muito a contribuir com suas perspectivas; e,

- Participar de congressos, cursos, palestras, encontros, grupos de estudos, leituras de materiais da área em que atua, e, escrever sobre suas experiências, valorizando e compartilhando do ensino e das aprendizagens decorrentes.

Enfim, o desenvolvimento do trabalho docente se fundamenta na procura incessante da atualização profissional, no aprimoramento de suas técnicas de ensino fundamentadas na Pedagogia e na Didática, que são instrumentos para conduzir a aprendizagem dos conteúdos e transformar a realidade do aluno para melhor. Fazer com que ele sinta sua evolução e progresso baseado no respeito e na condução eficiente do professor. Ambos aprenderão com suas experiências, dificuldades e êxitos. Este é o sagrado ato da evolução humana que em grande parte a universidade é responsável pela sua perpetuação.

\section{Referências}

BORUCHOVITCH, E. Estratégias de aprendizagem e desempenho escolar: considerações para a prática educacional. Psicologia: Reflexão e Crítica. São Paulo: Psicologia, 1999. 12(2), 361-376.

BRANDÃO, Carlos R. O que é educação. 40ª Reimp. São Paulo: Brasiliense, 2001. (coleção Primeiros Passos: 203). 116 p.

BRITO CRUZ, Carlos Henrique de. Pesquisa e Universidade. Disponível em :

$<$ www.iea.usp.br/observatorios/educacao . Acesso em 18/06/2009.

BRASIL. LDB no 9.394 de 1996. Brasília: Senado Federal, 1996.

CANDAU, Vera Maria (Org.). Rumo a uma nova Didática. 6.ed. Petrópolis (RJ): Vozes, 1994. 179.

CHARLOT, Bernard. Da relação com o saber, elementos para uma teoria. Trad. Bruno Magne. Porto Alegre: Artes Médicas, 2000). 93 p.

GANDIN, Danilo. Planejamento como prática educativa. 12. Ed. São Paulo: Loyola, 2002. $111 \mathrm{p}$.

GRÁCIO, M. L. F. \& ROSÁRIO, P. . Olhares dos estudantes sobre o que torna difícil aprender. In: MACHADO, C. L. S.; ALMEIDA, Gonçalves, M. \& RAMALHO, V. (Orgs.), Avaliação

Psicológica: formas e contextos. Braga (SP): Psiquilíbrios Edições, 2004. (pp.164-169). 
LIBÂNEO, José Carlos. Pedagogia e Pedagogos, para quê? 8.ed. São Paulo: Cortez, 2005. 208 p.

LUAIZA, C. Benito Almaguer. Educação, ensino e instrução: o que significam estas palavras. Disponível em: < http://br.monografias.com/trabalhos3/educacao-ensinoinstrucao/educacao-ensino-instrucao.shtml >. Acesso em; 15/06/2009.

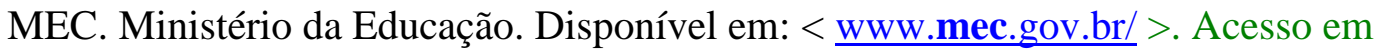
05/06/2009.

MEIRIEU, Philipe. Aprender...sim, mas como?. 7. ed. Porto Alegre: Artmed, 1998. 193 p.

PROA, Sérgio Espinosa. A tradição inovadora. Boletim técnico do SENAC. São Paulo: SENAC, 1995. V.. 21. N. 03. set-dez. 10 p.

SANTOS, Antonio Raimundo dos. Metodologia científica: a construção do conhecimento. 5. Ed. Rio de Janeiro: DP\&A, 2002.

SILVEIRA, Ricardo Jesus [et al.] Perfil do aluno: UEL - Universidade Estadual de Londrina. Londrina (PR): APC - Assessoria de Planejamento e Controle, 2003. 90 p. : il., $23 \mathrm{~cm}$. (Cadernos de Avaliação Institucional, $\mathrm{n}^{\circ} .3$ ). Disponível em:

< http://www.uel.br/proplan/perfil-aluno/perfil-aluno.pdf $>$. Acesso em 18/06/2009.

TARDIF, Maurice. Saberes docentes \& Formação profissional. 5. Ed. Petrópolis (RJ): Vozes, 2005. 325 p.

UEL. Universidade Estadual de Londrina. Disponível em:

< http://www.uel.br/proplan/perfil-aluno/perfil-aluno.pdf >. Acesso em: 17/06/2009.

WAGNER, Andresa G. Conhecimento empírico $x$ Conhecimento científico: uma abordagem simplificada. Disponível em: <

$<$ http://www.fameg.edu.br/estagio/conhecimento_empirico_x_conhecimento_cientifico.ppt\# 256,1,Conhecimento Empírico X Conhecimento Científico: >. Acesso em: 15/06/2009. 